\title{
DINAMIKA LUWENG BELIMBING, KAWASAN KARST GUNUNGSEWU PASCA SIKLON TROPIS CERMPAKA TAHUN 2017
}

\author{
Eko Haryono1, Ahmad Cahyadi2, Muchammad Amin Nurrohman', \\ Gemasakti Adzan', Lely Adriani Nasution' ${ }^{4}$ Husna Diah6, Risma Sari Septianingrum7 \\ 1,3,4,5Program Studi Ilmu Lingkungan, Sekolah Pascasarjana, Universitas Gadjah Mada \\ Jl. Bulaksumur, Depok, Sleman, D.I. Yogyakarta 55821, Indonesia \\ 1,2,6,7Kelompok Studi Karst, Fakultas Geografi, Universitas Gadjah Mada \\ Jl. Bulaksumur, Depok, Sleman, D.I. Yogyakarta 55821, Indonesia \\ 3,7Departemen Geografi Lingkungan, Fakultas Geografi, Universitas Gadjah Mada, \\ Jl. Bulaksumur, Depok, Sleman, D.I. Yogyakarta 55821, Indonesia \\ 4Program Studi Geografi, Fakultas Geografi, Universitas Gadjah Mada, \\ Jl. Bulaksumur, Depok, Sleman, D.I. Yogyakarta 55821, Indonesia \\ Email: ahmadcahyadi@geo.ugm.ac.id
}

\begin{abstract}
Abstrak
Siklon tropis cempaka yang terjadi pada tahun 2017 tidak hanya meninggalkan jejak berupa dampak bencana, tetapi juga pelajaran berharga tentang bencana banjir di kawasan karst serta dinamikan bentuklahan yang menyertainya. Salah satu kawasan yang terdampak parah siklon tersebut adalah Luweng Belimbing yang terletak di Desa Pacarejo, Kecamatan Semanu, Kabupaten Gunungkidul. Penelitian ini bertujuan untuk menganalisis dinamika Luweng Belimbing pasca Siklon Tropis Cempaka. Analisis dinamika dilakukan dengan menganalisis perubahan luas luweng berdasarkan kajian sebelumnya menggunakan hasil pencitraan pesawat tanpa awak, survei lapangan dan wawancara dengan masyarakat sekitar Luweng Belimbing. Hasil analisis menunjukkan bahwa dinamika dapat dibagi menjadi lima tahapan yang saling berurutan.
\end{abstract}

Kata Kunci: Siklon Tropis Cempaka, Dinamika Bentuklahan, Karst, Banjir, Luweng Belimbing

\begin{abstract}
Tropical cyclones Cempaka that occurred in 2017 not only left the impact of disasters but also valuable lessons about flooding in the karst region and the accompanying landform dynamics. One of the areas badly affected by the cyclone is Belimbing Doline located in Pacarejo Village, Semanu District, Gunungkidul Regency. This research aims to analyze the dynamics of Belimbing Doline after Tropical Cyclone Cempaka. Dynamics analysis is done by analyzing changes in doline area based on previous studies using drone imaging results, field surveys and interviews with communities around Belimbing Doline. The analysis shows that the dynamics can be divided into five sequential stages,
\end{abstract}

Keywords: Tropical Cyclone Cempaka, Landform Dynamic, Karst, Flood, Belimbing Doline 


\section{PENDAHULUAN}

Siklon Tropis Cempaka yang terjadi pada tahun 2017 telah menyebabkan banyak kerusakan di Kawasan Karst Gunungsewu (Cahyadi et al., 2019). Namun demikian, kejadian ini memberikan banyak pelajaran dan memberikan kontribusi terhadap pengembangan keilmuan khususnya di kawasan karst. hal ini terutama terkait dengan dinamika bentuklahan dan kerawanan bencananya.

Salah satu wilayah yang terdampak parah saat terjadi Siklon Tropis Cempaka adalah Kawasan Luweng Belimbing yang terletak di Desa Pacarejo, Kecamatan Semanu, Kabupaten Gunungkidul. Siklon tropis cempaka menyebabkan kawasan ini tergenang dengan kedalaman lebih dari 15 meter (Gambar 1) dan menyebabkan perluasan Luweng Belimbing sampai dengan $4.968 \mathrm{~m}^{2}$ (Nurteisa et al., 2018). Kondisi ini tentu menjadi menarik dari sisi Geologi dan Geomorfologi karena hal tersebut jarang sekali terjadi di Kawasan Karst Gunungsewu yang lebih dikenal sebagai kawasan yang sering menngalami kekeringan (Haryono et al., 2009; Fatchurohman \& Cahyadi, 2011; Cahyadi, 2016).
Kajian terkait dengan dinamika Luweng Belimbing akan memberikan sumbangsih berupa model perkembangan bentuklahan yang terletak pada zona transisi, yakni zona transisi antara Karst Gunungsewu dan kawasan non-karst (Basin Wonosari) (Cahyadi et al., 2018). Kajian ini akan memperkaya bahasan terkait dengan peran sungai alogenik terhadap perkembangan kawasan karst, khususnya pada bagian transisi. Haryono menyebutkan bahwa Kawasan Luweng Blimbing dahulu merupakan danau purba. Hal ini berarti bahwa penelitian tentang dinamika Luweng Belimbing juga akan memperkaya kajian kebumian yang sangat mendukung untuk dijadikan sebuah Geosite. Secara spasial, kawasan yang dikaji terletak di antara dua Geosite, yakni Geosite Kalisuci - Gua Jomblang dan Geosite Lembah Ngingrong - Galeri Taman Batu. Pengembangan kawasan ini menjadi geosite diharapkan dapat menjadi jembatan antara dua geosite, dan kemudian dapat dibentuk suatu kawasan yang komprehensif dengan berbagai objek wisata dan kajian kebumian yang saling bersinergi.

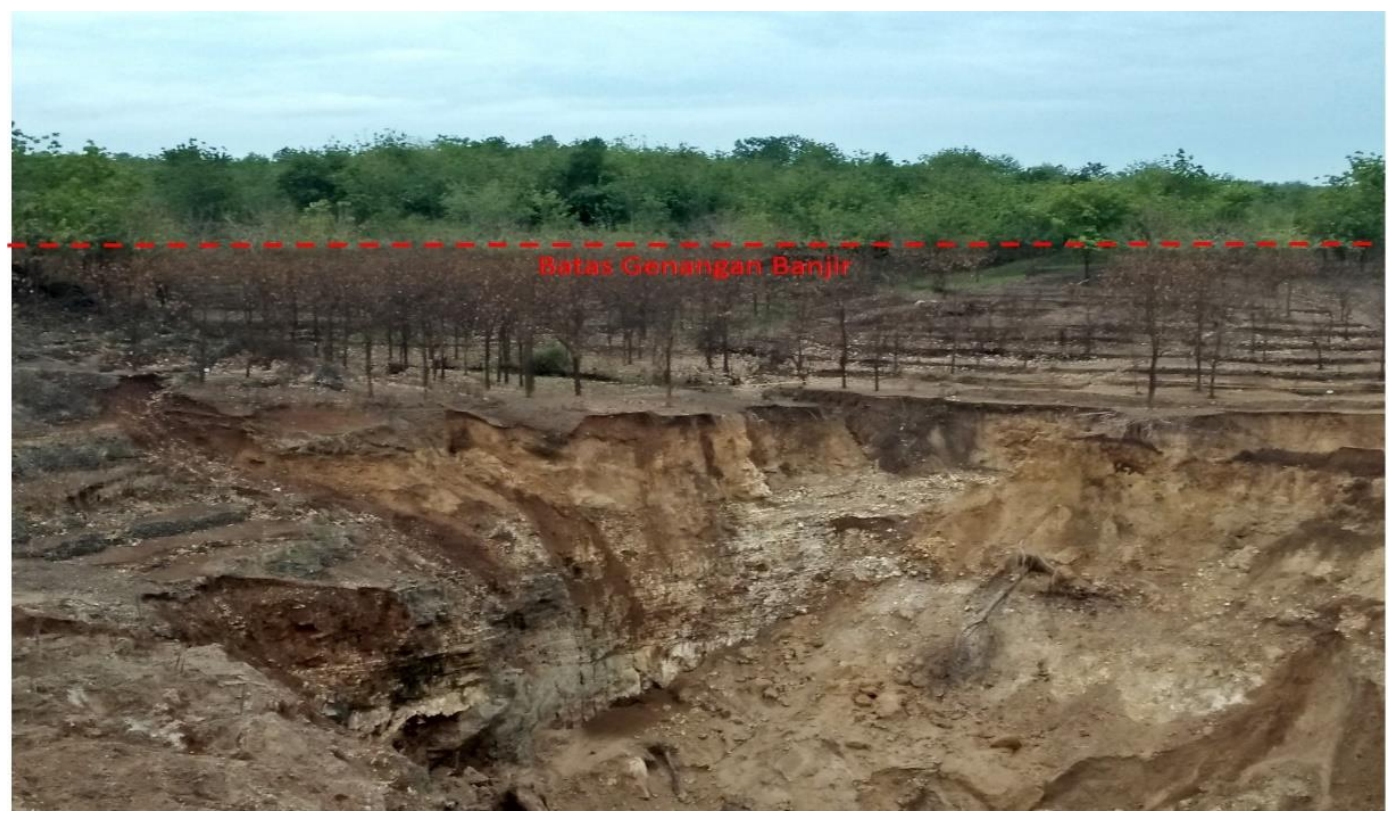

Gambar 1. Jejak Genangan Banjir Pasca Siklon Tropis Cempaka di Luweng Belimbing 
Selain terkait pada pengembangan keilmuan, aspek dinamika bentuklahan dan kebencanaan sangat layak mendapatkan perhatian untuk pengembangan suatu objek wisata kebumian dan pemanfaatan lain di masa mendatang. Hal ini agar dapat dirumuskan upaya pencegahan dan mitigasi bencana pada lokasi kajian. Oleh karenanya, penelitian ini bertujuan untuk menganalisis dinamika Luweng Belimbing yang terjadi pasca Siklon Tropis Cempaka.

\section{METODE PENELITIAN}

Kajian dinamika bentuklahan di Luweng Belimbing pasca Siklon Tropis Cempaka dilakukan dengan empat tahapan, yaitu: (1) menganalisis hasil kajian sebelumnya yang dilakukan oleh Nurteisa et al., (2018) yang melakukan kajian perubahan luasan Luweng Belimbing pasca Siklon tropis cempaka berdasarkan pada pemotretan secara temporal dengan dengan menggunakan pesawat tanpan awak, (2) melakukan analisis lapangan terhadap dinamika (proses dan hasil proses) yang terjadi di Luweng Belimbing, dan (3) melakukan wawancara dengan masyarakat sekitar Luweng Belimbing tentang kejadian yang terjadi pasca Siklon Tropis Cempaka. (4) merumuskan tahapan dinamika yang terjadi di Luweng Belimbing pasca Siklon Tropis Cempaka.

\section{HASIL DAN PEMBAHASAN}

Dalam konteks regional, lokasi Luweng Belimbing berada pada peralihan antara Fisiografi Karst Gunungsewu dan Basin Wonosari.Lokasi ini tepat berada pada patahan yang memisahkan keduanya (Gambar 2), sehingga nampak kontras meskipun memiliki formasi batuan yang sama (Haryono, 2011; Haryono et al., 2017) (Gambar 3). Namun demikian, secara detail Notosiswoyo dan Kusumayudha (1998) menyebutkan bahwa bagian utara Luweng Belimbing didominasi oleh gamping berlapis atau bioklastik, sedangkan pada bagian selatan Luweng Belimbing didominasi oleh gamping terumbu. Bagian selatan dari Luweng Belimbing nampak telah terbentuk perbukitan karst, sedangkan pada bagian utara Luweng Belimbing nampak wilayah yang datar sampai dengan landai yang menunjukkan belum berkembangnya topografi karst (Haryono, 2000; Kusumayudha et al., 2015).

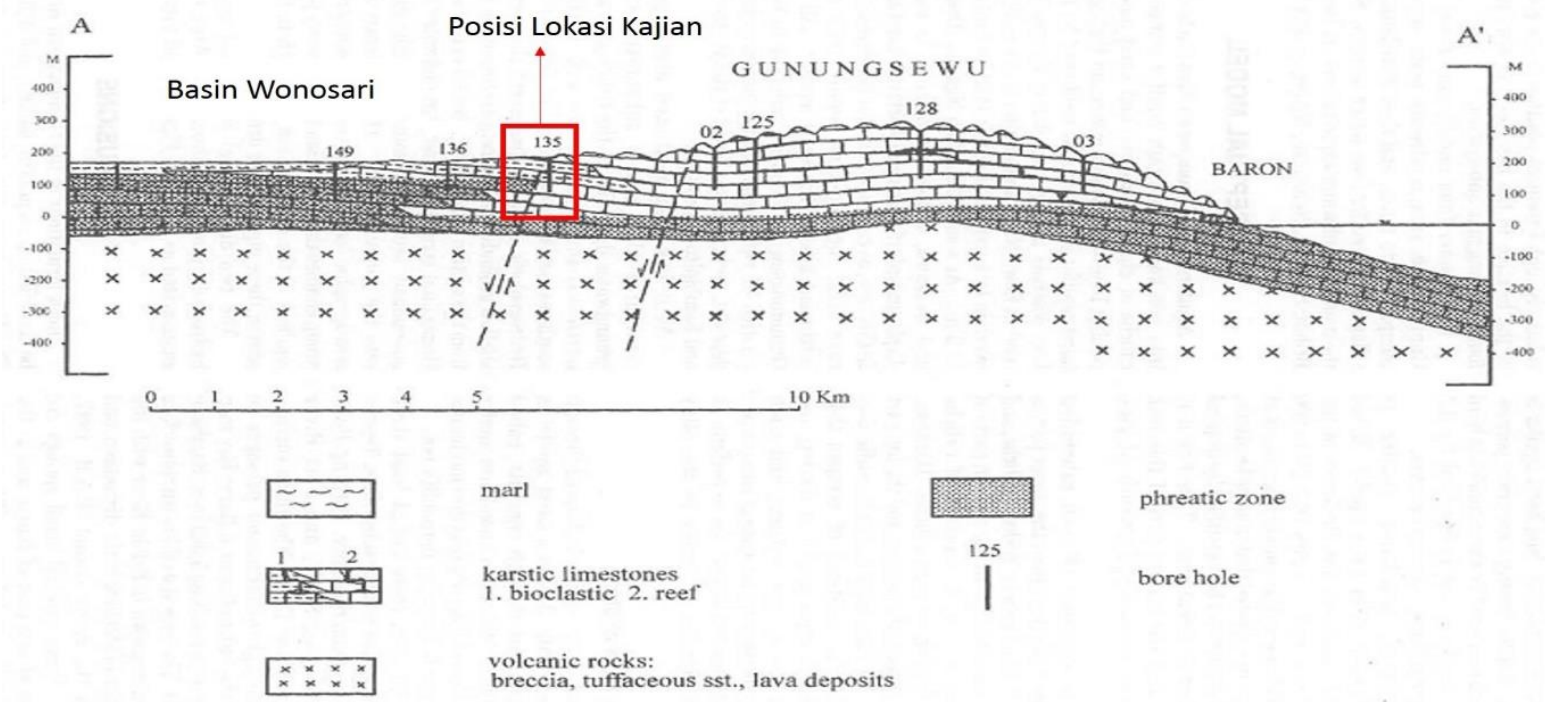

Gambar 2. Lokasi Luweng Belimbing Menempati Peralihan antara Basing Wonosari dan Karst Gunungsewu (Notosiswoyo dan Kusumayudha, 1998 dengan Modifikasi) 


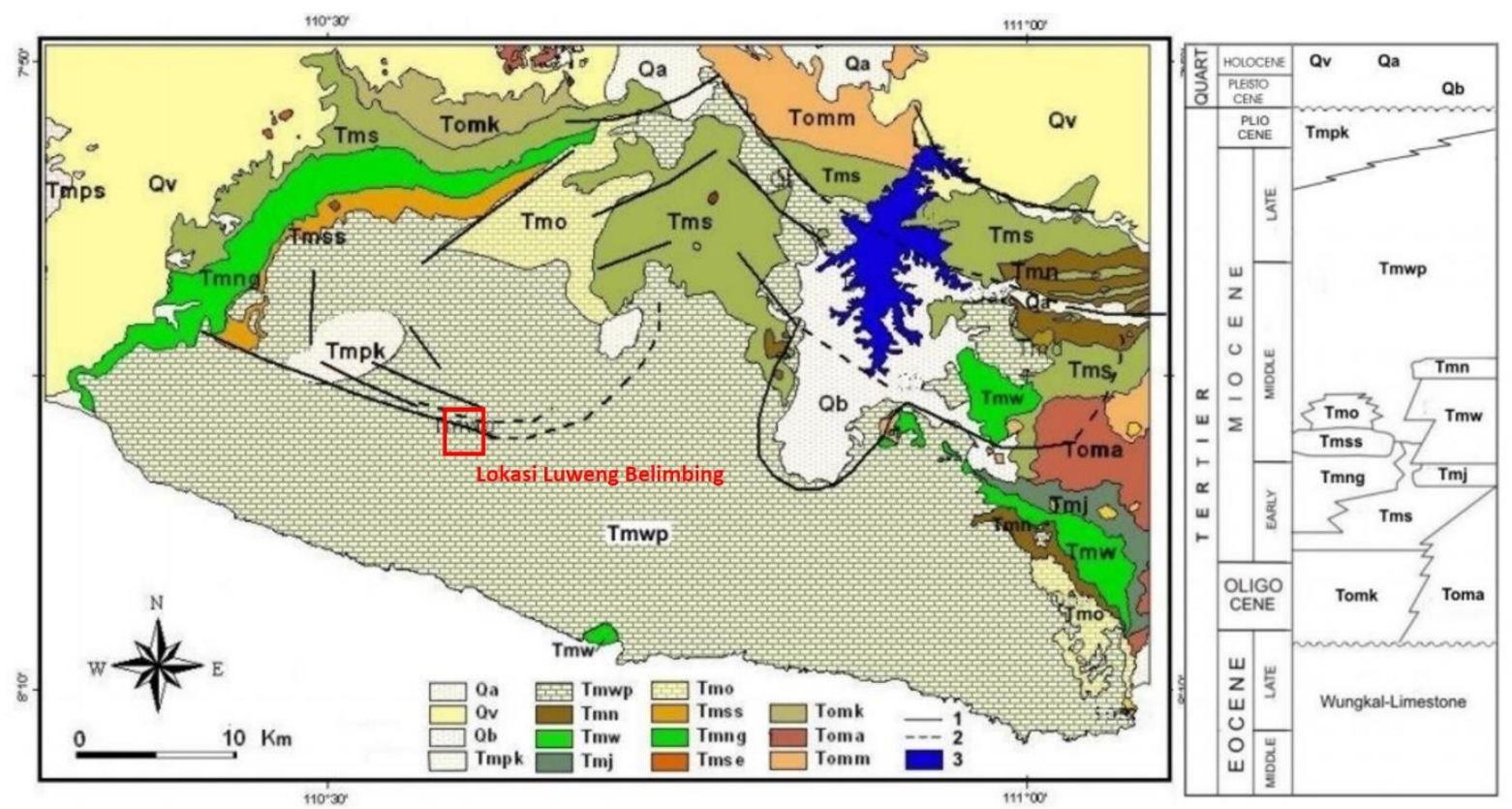

Gambar 3. Lokasi Luweng Belimbing secara Geologi Regional

(Modifikasi dari Haryono et al, 2017)

Berdasarkan hasil analisis yang telah dilakukan, setidaknya terdapat lima tahapan dinamika Luweng Belimbing yang terjadi pasca Siklon Tropis Cempaka. Kelimanya merupakan tahapan yang berurutan. Pemisahan tahapan ini untuk memudahkan memahami dinamika yang terjadi pada bentuklahan di lokasi kajian.

Tahapan pertama dari dinamika Luweng Belimbing pasca Siklon Tropis Cempaka adalah terjadinya banjir yang menggenangi Luweng Belimbing dan sekitarnya. Banjir disebabkan oleh dua hal, yaitu (1) penuhnya sistem sungai bawah tanah, sehingga air naik sampai ke permukaaan, dan (2) air yang berasal dari sungai alogenik tidak dapat masuk, sehingga terjadi genangan di lokasi kajian. Sungai alogenik yang menyebabkan terjadinya banjir adalah sungai alogenik yang mengalir ke Luweng Belimbing dan juga sungai alogenik yang masuk ke Ponor Tumbul di sebelah timur Luweng Belimbing.

Tahapan kedua adalah terjadinya surut yang terjadi dengan cepat, sehingga menyebabkan pengendapan material yang dibawa banjir dan runtuhan tebing Luweng Belimbing yang kemudian menyumbat ponor di bagian bawah Luweng Belimbing. Kondisi ini menyebabkan terbentuknya danau sebagai tahapan dinamika bentuklahan yang ketiga di lokasi kajian (Gambar 4).

Tahapan keempat dinamika bentuklahan di Luweng Belimbing adalah terjadinya amblesan pada bagian bawah danau yang kemudian menyebabkan terbukanya ponor yang kemudian mengatuskan air danau menuju ke sungai bawah tanah. Hal ini menyebabkan danau menjadi kering. Proses ini terjadi secara tibatiba dan dengan waktu yang sangat singkat. Hasil pengakuan warga bahwa pada saat kejadian terjadi suara yang keras dan getaran seperti terjadi gempa bumi.

Tahapan terkahir dari dinamika Luweng Belimbing pasca Siklon Tropis Cempaka adalah perluasan dinding Luweng Belimbing. Tahapan ini terjadi karena runtuhnya dinding Luweng Belimbing. Hasil kajian yang dilakukan oleh Nurteisa et 


\section{geøgrafi}

al., (2018) menunjukkan bahwa penambahan luas sampai dengan Bulan Februari 2018 adalah sebesar $4.968 \mathrm{~m}^{2}$ (Gambar 5). Penambahan luas ini semakin menurun dilihat dari dua kali hasil pemotretan dengan pesawat tanpa awak. Periode kejadian Siklon Tropis Cempaka sampai dengan 06 Desember 2017 diketahui
DOI: 10.24114/jg.v12i01.14769 e-ISSN: 2549-7057 | p-ISSN: 2085-8167

bahwa luasan Luweng Belimbing bertambah $4.500 \mathrm{~m}^{2}$, sedangkan pemotretan yang kedua yang dilakukan pada tanggal 04 Februari 2018 menunjukkan bahwa perluasan Luweng Belimbing hanya bertambah $468 \mathrm{~m}^{2}$. Hal ini menunjukkan penambahan luas yang semakin menurun.

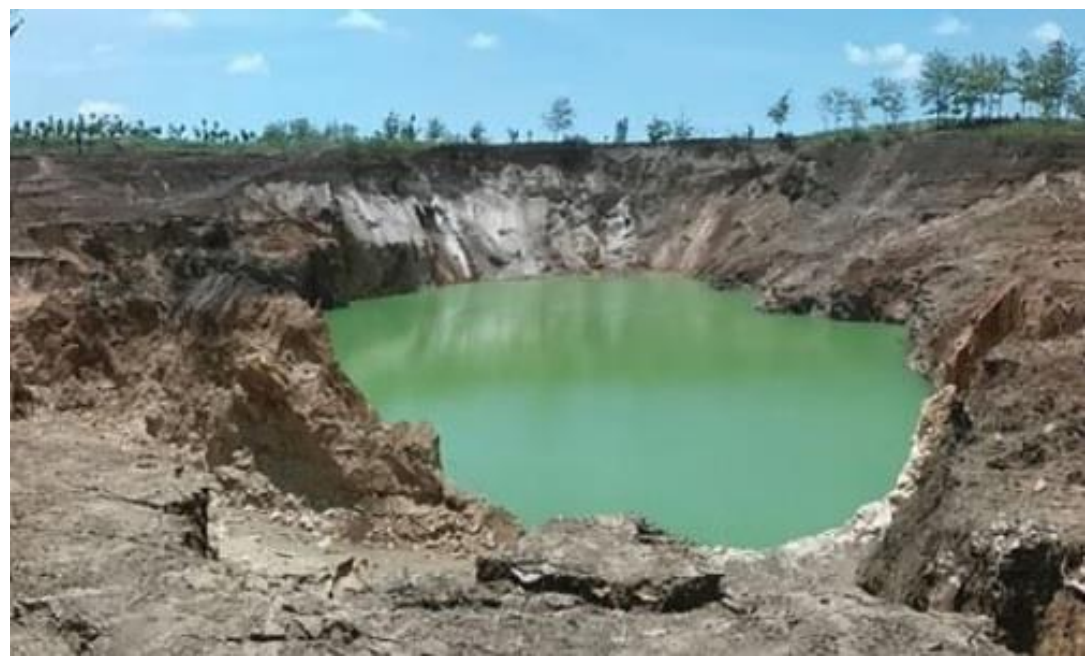

Gambar 4. Danau yang Terbentuk di Luweng Belimbing Pasca Siklon Tropis Cempaka (Sumber: https://jogja.tribunnews.com)

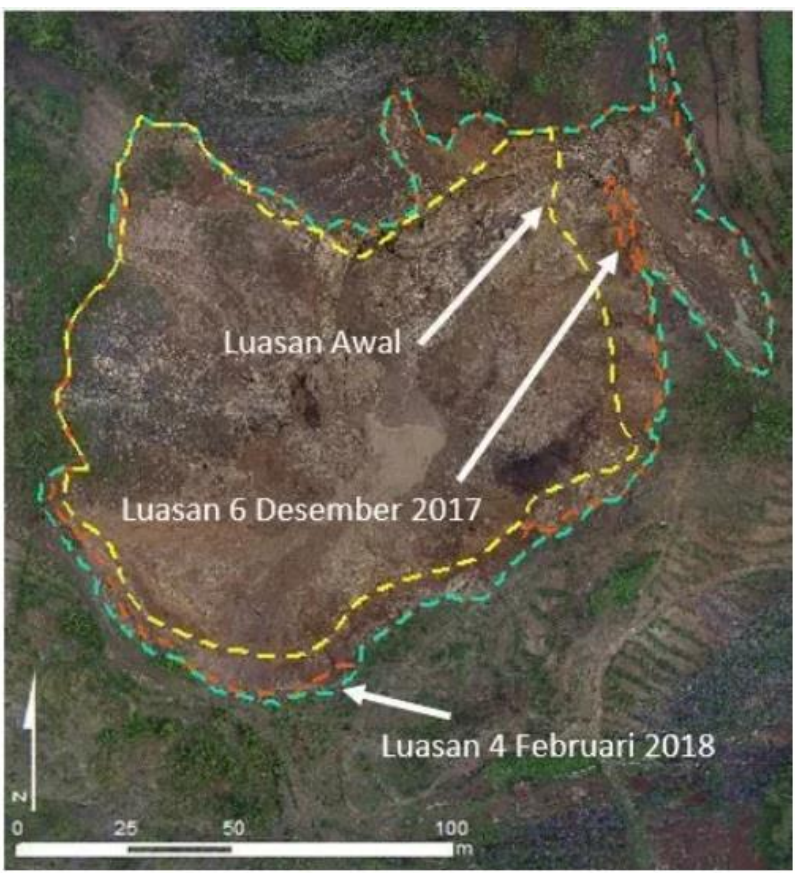

Gambar 5. Perubahan Luasan Luweng Belimbing Pasca Siklon Tropis Cempaka (Nurteisa et al., 2018) 


\section{KESIMPULAN}

Penelitian ini menemukan lima tahap dinamika bentuklahan yang terjadi di Luweng Belimbing pasca Siklon Tropis Cempaka, yaitu:

1. terjadinya banjir akibat luapan sungai bawah tanah dan Sungai Alogenik Tumbul yang berada di sebelah timur Luweng Belimbing;

2. terjadinya surut dengan cepat yang diikuti dengan pengendapan material yang dibawa selama banjir dan runtuhnya dinding luweng, sehingga ponor Luweng Belimbing tersumbat;

3. tahap ketiga adalah tahapan ketika terbentuk danau dalam waktu beberapa hari;

4. tahap keempat terjadi amblesan yang membuka ponor, sehingga danau menjadi surut dan kering;

5. tahap terakhir adalah tahapan perluasan dinding Luweng Belimbing yang sampai saat ini masih terjadi meskipun dengan intensitas yang semakin kecil.

\section{UCAPAN TERIMAKASIH}

Penelitian ini merupakan bagian kecil dari hibah penelitian dosen Sekolah Pascasarjana UGM tahun 2019 dengan judul "Analisis Pembentukan Bentanglahan di Kawasan Luweng Belimbing, Kabupaten Gunungkidul sebagai Upaya Penguatan Geopark Gunungsewu.". Penulis mengucapkan terima kasih kepada pihak Sekolah Pascasarjana Universitas Gadjah Mada yang telah memberikan hibah penelitian kepada kami. Tidak lupa penulis mengucapkan terima kasih kepada Kepala Dukuh Serpeng dan Kepala Dukuh Nampo, Desa Pacarejo, Kecamatan Semanu, Kabupaten Gunungkidul atas bantuannya selama penulis melakukan penelitian.

\section{DAFTAR PUSTAKA}

Cahyadi, A. (2016). Peran Telaga dalam Pemenuhan Kebutuhan Air di Kawasan Karst Gunungsewu Pasca Pembangunan Jaringan Air Bersih. Geomedia, 14(2): 23-33.

Cahyadi, A.; Riyanto, I.A.; Irshabdillah, M.R. dan Firizqi, F. (2018). Inventarisasi dan Karakterisasi Sistem Sungai Alogenik di Kawasan Karst Gunungsewu Kabupaten Gunungkidul. Laporan Penelitian Hibah Dosen. Yogyakarta: Fakultas Geografi, Universitas Gadjah Mada.

Cahyadi, A.; Haryono, E.; Adji, TN., Widyastuti, M.; Riyanto, IA.; Nurteisa, YT.; Fatchurohman, H.; Agniy, RF.; Nurkholis, A.; Naufal, M.; dan Nurjani, E. (2019). Groundwater Flooding due to Tropical Cyclone Cempaka in Ngreneng Karst Window, Gunungsewu Karst Area, Indonesia. International Conference on Energy, Environment, Epidemiology, and Information System 2019. Semarang: Universitas Diponegoro.

Fatchurohman, H. dan Cahyadi, A. (2011). Strategi Adaptasi Masyarakat Terhadap Bencana Kekeringan di Kawasan Karst Kecamatan Panggang, Gunungkidul. in Sudarmadji; Haryono, E.; Adji, T.N.; Widyastuti, M.; Harini, R.; Nurjani, E.; Cahyadi, A. \& Nugraha, H. (Eds). 2011. Ekologi Lingkungan Kawasan Karst Indonesia. Yogyakarta: Deepublish.

Haryono, E. (2000). Some Properties of Epikarst Drainage System in Gunung Kidul Regency, Yogyakarta Special Province, Indonesia. The Indonesian Journal of Geography, 32, 75-86. 
Haryono, E; Adji, T.N. dan Widyastuti, M. (2009). Problems of Telaga (Doline Pond) in Gunungsewu Karst, Java, Indonesia. in White, W.B. (Ed). 2009. Proceeding $15^{\text {th }}$ International Congress of Speleology, Vol. II. Texas: UIS.

Haryono, E. (2011). Introduction to Gunungsewu Karst. Field Guide of Asian Trans-Disciplinary Karst Conference. Yogyakarta: Kelompok Studi Karst, Fakultas Geografi, Universitas Gadjah Mada.

Hayono, E.; Barianto, D.H. dan Cahyadi, A. (2017). Hidrogeologi Kawasan Karst Gunungsewu: Panduan Lapangan Fieldtrip PIT PAAI ke-2. Yogyakarta: Perhimpunan Ahli Airtanah Indonesia (PAAI).

Haryono, E. (2016). Speleogenesis Luweng Serpeng, Kecamatan Semanu, Kabupaten Gunungkidul. Laporan Penelitian Hibah Penelitian Dosen. Yogyakarta: Fakultas Geografi Universitas Gadjah Mada.
Kusumayudha, S.B.; Setiawan, J.; Ciptahening, A.N. \& Septianta, P.D. (2015). Geomorphologic Model of Gunungsewu Karst, Gunung Kidul Regency, Yogyakarta Special Territory, Indonesia: The Role of Lithologic Variation and Geologic Structure. Journal of Geological Resource and Engineering, 1, 1-7.

Notosiswoyo, S. and Kusumayudha, S.B. (1998). Hydrogeology of The Gunungsewu Karstic Area, Central Java, Indonesia: A Conceptual Model. Proceeding of Ninth Regional Congress on Geology, Mineral and Energy Resources of South East Asia. Kuala Lumpur.

Nurteisa, YT.; Cahyadi, A.; Fatchurohman, H. dan Dwiatmaja, E. (2018). Tanggapan terhadap Amblesan Tanah di Kawasan Karst Kabupaten Gunungkidul. https://www.mitrageotama.com/tang gapan-amblesan-tanah-di-kawasankarst-kabupaten-gunungkidul 